\title{
Morfogênese e estrutura de azevém anual Estanzuela 284 submetido a dois intervalos
}

\section{entre pastoreios}

\author{
Structural and morphogenical characteristics of Italian ryegrass Estanzuela 284 submitted to two \\ intervals between grazing
}

Morfogénesis y estructura del Raigrás Estanzuela 284 sometida a dos intervalos entre pastoreo

Recebido: 20/07/2021 | Revisado: 29/07/2021 | Aceito: 30/07/2021 | Publicado: 05/08/2021

Anna Carolina Cerato Confortin
ORCID: https://orcid.org/0000-0001-9422-1629
Instituto Federal de Educação, Ciência e Tecnologia Farroupilha, Brasil
E-mail: anna.confortin@iffarroupilha.edu.br
Janaína de Godois Sanches
ORCID: https://orcid.org/0000-0003-0289-2236
E-mail: janainagodoissanches@ @mail.com
Adriana Macedo da Silva
Instituto Federal de Educação, Ciência e Tecnologia Farrouilha, Brasi
ORCID: https://orcid.org/0000-0001-9466-282X
E-mail: adriana.macedo94@ gmail.com
Ítalo Marques Monteiro
Instituto Federal de Educação, Ciência e Tenologia Farroupilha, Brasil
ORCID: https://orcid.org/0000-0002-2645-0734
Universidade Federal do Rio Grande do Sul, Brasil
E-mail: zootecnia.italo.m@gmail.com

\section{Resumo}

Este estudo foi conduzido com objetivo de analisar a influência de diferentes intervalos entre pastoreio sobre as características morfogênicas e estruturais de azevém anual (Lolium multiflorum Lam) cv. Estanzuela 284. O delineamento foi inteiramente casualizado com dois tratamentos ("FIXO"- ocupação da pastagem em intervalos fixos de 28 dias e "DEF"- ocupação da pastagem em intervalo determinado pelo tempo para o acúmulo térmico equivalente a duração da elongação foliar de azevém) e três repetições. A carga animal foi ajustada para a remoção de $50 \%$ da massa de forragem inicial em cada período de pastejo. Os animais experimentais foram bezerras de corte da raça Brangus, com idade de oito meses e peso corporal inicial de $150 \pm 3,9 \mathrm{Kg}$, e um número variável de bezerras para regular a carga animal. Os dados foram submetidos à análise de variância, a nível de 5\% de significância. Os intervalos entre pastoreios não afetaram as taxas de senescência (TSF), aparecimento (TAF) e de elongação (TEF) foliar. A pastagem manejada com intervalos baseados na duração de elongação foliar apresentou maior porcentagem de folhas e também, com o avanço do ciclo, maior relação folha: colmo. Não se recomenda a adoção de intervalos entre pastoreio fixo para o manejo da pastagem de azevém anual.

Palavras-chave: Arquitetura do dossel; Duração da elongação foliar; Lotação rotacionada; Perfilhos marcados; Relação folha-colmo.

\begin{abstract}
This study was carried out to analyze the influence of different intervals between grazing on the morphogenic and structural characteristics of Italian ryegrass (Lolium multiflorum Lam) cv. Estanzuela 284. The experimental design was completely randomized with two treatments ("FIXO" - pasture occupation at fixed intervals of 28 days and "DEF" - pasture occupation at an interval determined by the time for thermal accumulation equivalent to the duration of ryegrass leaf elongation) and three repetitions. The stocking rate was adjusted to remove $50 \%$ of the initial forage mass in each grazing period. The experimental animals were Brangus beef heifers, aged eight months and initial body weight of $150 \pm 3.9 \mathrm{~kg}$, and a variable number of heifers to regulate the stocking rate. Data were submitted to analysis of variance at a 5\% significance level. The intervals between grazing did not affect senescence (TSF), appearance (TAF) and leaf elongation (TEF) rates. The pasture managed with intervals based on the duration of leaf elongation presented a higher percentage of leaves and with the advance of the cycle, a higher leaf: stem ratio. The adoption of fixed intervals between grazing for the management of annual ryegrass pasture is not recommended.
\end{abstract}

Keywords: Canopy architecture; Duration of leaf elongation; Leaf/ stem ratio; Marked tillers; Rotational stocking. 


\section{Resumen}

Este estudio se llevó a cabo para analizar la influencia de diferentes intervalos entre el pastoreo sobre las características morfogénicas y estructurales del Raigrás (Lolium multiflorum Lam.) Estanzuela 284. El diseño fue completamente al azar con dos tratamientos ("FIXO" - ocupación del pasto a intervalos fijos de 28 días y "DEF" ocupación del pasto en un intervalo determinado por el tiempo de acumulación térmica equivalente a la duración del alargamiento de la hoja del raigrás) y tres repeticiones. La carga animal se ajustó para eliminar el 50\% de la masa de forraje inicial en cada período de pastoreo. Los animales experimentales fueron novillas de carne Brangus, de ocho meses de edad y peso corporal inicial de $150 \pm 3,9 \mathrm{~kg}$, y un número variable de novillas para regular la carga animal. Los datos se sometieron a análisis de varianza a un nivel de significancia del 5\%. Los intervalos entre pastoreo no afectaron las tasas de senescencia (TSF), apariencia (TAF) y elongación foliar (TEF). El pasto manejado con intervalos en función de la duración del alargamiento foliar presentó un mayor porcentaje de hojas y también, con el avance del ciclo, una mayor relación hoja: tallo. No se recomienda la adopción de intervalos fijos entre el pastoreo para el manejo de los pastos anuales de raigrás.

Palabras clave: Arquitectura de dosel; Duración del alargamiento de la hoja; Media rotada; Macollos marcados; Relación hoja-vástago.

\section{Introdução}

O azevém anual se caracteriza por ser uma espécie rústica e vigorosa, considerada naturalizada em muitas regiões sulbrasileiras, que perfilha em abundância e é produtiva, podendo superar as demais espécies de inverno quando bem fertilizada (Fontaneli et al., 2012). É uma gramínea tolerante ao pisoteio e com ampla versatilidade de uso, podendo ser utilizada para pastoreio, cultivada em extreme, compondo pastagens consorciadas e, sobressemeada em pastagens naturais dos campos sulinos, como estratégia para o melhoramento do campo nativo no período de outono e inverno.

O cultivar Estanzuela 284, por sua vez, apresenta precocidade produtiva, bem como, elevada produção de folhas e matéria seca acumulada em relação a outros cultivares (Tonetto et al., 2011). Tal particularidade pode ser interessante para sistemas de integração lavoura-pecuária onde a pastagem de inverno precede a implantação da cultura de verão e se faz necessário escolher cultivares forrageiros que aliem elevada produção de forragem, em um ciclo curto, com características estruturais favoráveis ao elevado desempenho animal.

O manejo da pastagem sob o método de pastoreio com lotação rotacionada pode ser uma alternativa interessante para a obtenção de maior produção de forragem (Fernandes et al., 2015). Muitas pecuaristas ainda adotam intervalos fixos de descanso da pastagem como forma de facilitar o planejamento do pastoreio rotacionado. Todavia, Euclides et al. (2014) argumentam que esta estratégia pode restringir a produção animal, pois não gera padrão uniforme de resposta fisiológica da planta, resultando em dosséis de estrutura variável. Esse critério desconsidera os ritmos de crescimento das plantas e, assim, pode trazer prejuízos à produção, estrutura do pasto e qualidade da forragem produzida.

Quadros et al. (2011) argumentam que o uso de intervalo entre pastoreios baseado na duração de vida das folhas tem sido recomendado por permitir manter índice de área foliar mais próximo da máxima eficiência de interceptação luminosa e máxima taxa de crescimento, porém pode acarretar em redução da qualidade da forragem oferecida, ao passo que ultrapassa o ponto em que as taxas de expansão de novos órgãos da planta são ótimas. Assim sugerem como alternativa a utilização da duração de elongação foliar como critério para os períodos de descanso recomendáveis.

A partir da hipótese de que intervalos entre pastoreios com tempo equivalente à duração da elongação foliar favorecem a estrutura do dossel, este estudo foi conduzido com objetivo de analisar a influência de diferentes intervalos entre pastoreio (fixo ou baseado na duração da expansão foliar) sobre as características morfogênicas e estruturais de azevém anual (Lolium multiflorum Lam.) cv. Estanzuela 284.

\section{Metodologia}

Este trabalho consiste em uma pesquisa experimental de natureza quantitativa (Pereira et al., 2018). O experimento foi realizado em área experimental do Instituto Federal Farroupilha Campus Alegrete, com coordenadas geográficas 2942’49.51” 
S e 55²'02.71", no período compreendido entre maio e novembro de 2016. O solo da área é classificado como Argissolo Vermelho Distrófico Típico (EMBRAPA, 2016). As amostras de solo, coletadas de 0-10 $\mathrm{cm}$ de profundidade, revelaram as seguintes características: pH-H2O: 4,9; \% argila: $22 \mathrm{~m} / \mathrm{v} ; \mathrm{K}: 100 \mathrm{mg} / \mathrm{dm}^{3} ; \% \mathrm{MO}: 1,5 \mathrm{~m} / \mathrm{v} ; \mathrm{Al}: 3,1 \mathrm{cmol} / \mathrm{dm}^{3} ; \mathrm{Ca}: 2,9$ cmol/ $/ \mathrm{dm}^{3} ; \mathrm{P}: 17,8 \mathrm{mg} / \mathrm{dm}^{3} ; \mathrm{Mg}: 1,0 \mathrm{cmol} / \mathrm{dm}^{3} ; \mathrm{CTC} \mathrm{pH}$ 7: 7,3. De acordo com Köppen, o clima da região é classificado como (Cfa) subtropical úmido. Os dados climatológicos referentes ao período experimental foram obtidos na estação meteorológica automática instalada no Campus (INMET, 2016).

A área experimental foi constituída de seis parcelas, com área medindo $18 \times 6 \mathrm{~m}$ com semeadura, a lanço, em quatro de maio de 2016 e densidade de semeadura de $20 \mathrm{Kg} / \mathrm{ha}$ de sementes de azevém anual (Lolium multiflorum Lam.) cv. Estanzuela 284, em cultivo exclusivo. As adubações realizadas nas áreas experimentais seguiram as recomendações da Comissão de Química e Fertilidade do Solo RS/SC (2004), a adubação de cobertura de 200 kg de N na forma de ureia.

O delineamento experimental utilizado foi o inteiramente casualizado com dois tratamentos e três repetições de área. Os tratamentos foram dois intervalos de descanso da pastagem, simulando método de pastoreio com lotação rotacionada: intervalo "FIXO", que consistiu na ocupação da pastagem em intervalos fixos a cada 28 dias; "DEF", que consistiu na ocupação da pastagem em intervalos determinados pelo tempo de acúmulo térmico equivalente a duração de elongação foliar de azevém (240 graus dia; Confortin et al., 2010).

A soma térmica acumulada entre pastoreios foi obtida por meio de somatórios das somas térmicas diárias (STd) no período da avaliação, calculadas como: $\mathrm{STd}=(\mathrm{Tmed}-\mathrm{Tb})^{*} 1 \mathrm{dia}$, em que, Tmed corresponde à temperatura média diária e $\mathrm{Tb}$, corresponde à temperatura base de crescimento azevém, que equivale a $5{ }^{\circ} \mathrm{C}$. Se a temperatura média for menor que a temperatura base de crescimento, considera-se que a temperatura média é igual à temperatura base.

A primeira ocupação da pastagem ocorreu quando a massa de forragem atingiu $1.800 \mathrm{Kg} / \mathrm{ha}$ de MS. Os ciclos de pastejo ao longo da utilização da pastagem foram denominados de períodos. A carga animal foi ajustada de acordo com Heringer e Carvalho (2002), com vistas à remoção de 50\% da massa de forragem inicial. Os animais experimentais foram seis novilhas da raça Brangus, com oito meses de idade e peso médio inicial de $150 \mathrm{~kg} \pm 3,9 \mathrm{~kg}$.

A altura do dossel $(\mathrm{cm})$ foi medida em 20 pontos por parcela com o auxílio de régua graduada, em $\mathrm{cm}$, antes e depois de cada ocupação da pastagem. Para determinar a massa de forragem foram realizados cortes, em três áreas de $0,25 \mathrm{~m}^{2}$ por parcela, delimitados por quadrado de moldura metálica. A partir das amostras provenientes dos cortes, foi estimada a composição botânica e morfológica do pasto, por meio da separação manual dos componentes: folha (lâmina) e colmo de azevém (bainha foliar e colmo), material morto, inflorescências e outras espécies. Todas as amostras foram pesadas e secas em estufa com circulação de ar forçada a $55^{\circ} \mathrm{C}$, por $72 \mathrm{~h}$. A proporção de cada componente foi calculada conforme sua participação no peso de amostras verde e seca e a massa de cada componente estrutural $(\mathrm{kg} / \mathrm{ha}$ de $\mathrm{MS})$, obtida multiplicando-se o percentual do mesmo pela massa de forragem da área. A relação folha/colmo foi obtida por meio da razão entre a massa de lâminas foliares e a massa de colmos.

Para as avaliações de variáveis morfogênicas e estruturais do pasto foi utilizada a técnica de "perfilhos marcados" descrita por Carrère et al. (1997). A cada sete dias, foram mensurados em 15 perfilhos marcados, distribuídos em transectas, a altura do pseudocolmo $(\mathrm{cm})$, o comprimento e número de lâminas foliares expandidas e em expansão, além de sua condição (em senescência ou não e intacta ou desfolhada). Folhas expandidas foram medidas a partir de sua lígula e as folhas em expansão, a partir da lígula da última folha completamente expandida. Nas folhas em senescência, foi considerado apenas o comprimento da parte verde da lâmina foliar. As taxas de expansão (TEF) e senescência (TSF) foliar, em cm/GD, foram calculadas por meio da razão entre a expansão ou senescência média do perfilho entre duas avaliações consecutivas e a soma térmica acumulada no mesmo período. A taxa de aparecimento foliar (TAF) considerou-se como o valor do coeficiente angular da regressão entre o número de folhas produzidas por um perfilho e a soma térmica acumulada no período correspondente. A 
profundidade de lâminas foliares (PL) foi calculada pela diferença entre a altura do dossel e a altura do pseudocolmo médios do dossel.

Para comparar os tratamentos, as variáveis que apresentaram normalidade foram submetidas à análise de variância pelo procedimento Mixed do programa estatístico $\mathrm{SAS} 囚$ Versão 9.4. O modelo matemático da análise foi o seguinte: Yijk $=\mu$ $+\mathrm{Ti}+\mathrm{Cj}+\mathrm{TC}(\mathrm{ij})+$ eijk; onde: Yijk = variável dependente; $\mu$ = média; $\mathrm{Ti}=$ efeito do tratamento; $\mathrm{Cj}=$ efeito do período; $\mathrm{TCij}$ $=$ interação tratamento $*$ período; eijk $=$ erro. Foi realizado um teste de seleção de estruturas de covariâncias, utilizando o critério de informação Bayesiano (BIC) para determinar o modelo que melhor representasse os dados. As médias, quando verificadas diferenças (5\%), foram comparadas pelo teste de Tukey. A interação Tratamentos x Período foi desdobrada em nível de 5\% de significância.

\section{Resultados e Discussão}

As datas de ocupação da pastagem foram 27/07; 25/08 e 22/09/2016 para o intervalo entre pastoreios "FIXO" e 27/07; $17 / 08$ e $08 / 09 / 2016$ para o intervalo "DEF". As temperaturas médias diárias foram de $14,2^{\circ} \mathrm{C}, 16,5^{\circ} \mathrm{C}$ e $15,6^{\circ} \mathrm{C}$ para os meses de julho, agosto e setembro, respectivamente. A precipitação pluviométrica durante o período experimental foi de $391 \mathrm{~mm}$.

Houve interação entre intervalos de pastoreios e períodos $(\mathrm{P}<0,05$; Tabela 1) para as variáveis: massa de forragem ( $\mathrm{kg} / \mathrm{ha}$ de MS), massa de folhas (kg/ha de MS), massa de material morto ( $\mathrm{kg} / \mathrm{ha}$ de MS), relação folha: colmo. Ao longo dos períodos de utilização da pastagem se observa um aumento da massa de forragem. Isso se deve à elevação dos teores de matéria seca do pasto, bem como, acúmulo de colmos ao longo de ciclo fenológico da gramínea. Tal condição também se deve ao critério de manejo adotado que previa a remoção de $50 \%$ da massa de forragem inicial do pasto a cada ocupação da pastagem. Para Reis et al. (2016), o manejo de pastagens que permite uma quantidade de resíduo, composto por folhas de alta eficiência fotossintética, possibilitará à planta forrageira recuperar-se rapidamente ao corte ou pastejo, apresentando menor dependência de suas reservas orgânicas.

A pastagem manejada com o intervalo de duração de elongação foliar "DEF" apresentou maior massa de folhas no segundo período de ocupação da pastagem. Uma elevada proporção de folhas no dossel é muito importante haja visto que há preferência de seleção deste componente estrutural por bovinos em pastejo, possivelmente porque nas folhas se concentram as maiores porções de nutrientes na planta (Carvalho et al. 2001). A maior massa de folhas na pastagem contribui para a produção de forragem em quantidade e qualidade (Silva, 2015). 
Tabela 1. Variáveis estruturais do pasto de azevém anual cv. Estanzuela 284, sob lotação rotativa, de acordo com em intervalos entre pastoreios e períodos.

\begin{tabular}{|c|c|c|c|c|}
\hline \multirow{2}{*}{$\begin{array}{l}\text { Intervalos entre } \\
\text { pastoreios }\end{array}$} & \multicolumn{3}{|c|}{ Períodos } & \multirow{2}{*}{ EPM } \\
\hline & 1 (julho) & 2 (agosto) & 3 (setembro) & \\
\hline \multicolumn{5}{|c|}{ Massa de Forragem (kg/ha de MS) } \\
\hline FIXO & $1870,5 \mathrm{Ca}$ & $3156,1 \mathrm{Ba}$ & $4920,9 \mathrm{Aa}$ & \multirow{2}{*}{213,3} \\
\hline DEF & $2190,8 \mathrm{Ba}$ & $3710,1 \mathrm{Aa}$ & $4064,5 \mathrm{Ab}$ & \\
\hline \multicolumn{5}{|c|}{ Massa de Folhas (kg/ha de MS) } \\
\hline FIXO & $1364,30 \mathrm{Ba}$ & $1442,5 \mathrm{Bb}$ & $2229,9 \mathrm{Aa}$ & \multirow{2}{*}{78,9} \\
\hline DEF & $1443,74 \mathrm{Ba}$ & $2131,8 \mathrm{Aa}$ & $2286,2 \mathrm{Aa}$ & \\
\hline \multicolumn{5}{|c|}{ Massa de material morto (kg/ha de MS) } \\
\hline FIXO & $86,50 \mathrm{Ca}$ & $407,9 \mathrm{Ba}$ & 943,9 Aa & \multirow{2}{*}{64,5} \\
\hline DEF & $131,9 \mathrm{Ba}$ & $301,2 \mathrm{ABa}$ & $355,5 \mathrm{Ab}$ & \\
\hline \multicolumn{5}{|c|}{ Relação folha: colmo } \\
\hline FIXO & $3,6 \mathrm{Aa}$ & $1,1 \mathrm{Bb}$ & $1,4 \mathrm{Bb}$ & \multirow{2}{*}{0,2} \\
\hline \multirow[t]{2}{*}{ DEF } & $3,0 \mathrm{Aa}$ & $1,9 \mathrm{Ba}$ & $1,6 \mathrm{Ba}$ & \\
\hline & & de de lâmin & & \multirow{3}{*}{1,5} \\
\hline FIXO & $21,57 \mathrm{Ab}$ & $20,62 \mathrm{Ab}$ & $9,19 \mathrm{Bb}$ & \\
\hline DEF & $27,97 \mathrm{Ba}$ & $36,97 \mathrm{Aa}$ & $32,59 \mathrm{ABa}$ & \\
\hline
\end{tabular}

EPM= Erro Padrão da Média. Médias seguidas de letras distintas diferem pelo teste de Tukey, em que minúsculas distintas nas colunas indicam diferenças significativas $(\mathrm{P}<0,05)$ entre os tratamentos em cada período e maiúsculas distintas nas linhas indicam diferença significativas $(\mathrm{P}<0,05)$ entre os períodos dentro de cada tratamento.

Fonte: Autores

Quando o intervalo entre pastoreio foi equivalente à duração de elongação foliar, o pasto apresentou menor valor do componente material morto no terceiro ciclo de ocupação da pastagem (Tabela 1). Isso porque o intervalo adotado permitiu a utilização da pastagem antes das plantas apresentarem maior senescência. Por outro lado, o intervalo entre pastoreios fixo acarretou em um maior acúmulo térmico entre ocupações da pastagem e maior acúmulo de material senescente no dossel.

Manejos que resultem em maior acúmulo de material senescente não são desejáveis, pois implicam na redução da qualidade da forragem, tanto por meio da redução da concentração de nutrientes nos tecidos vegetais em senescência, quanto pela redução no consumo voluntário deste material. Prache e Peyraund (2001) demostram que a presença de material morto no dossel interfere na negativamente na ingestão da forragem, mais precisamente reduzindo a profundidade do bocado. Esta condição também é reforçada por Jochims e Ludtke (2020) ao afirmarem que, de maneira geral, quanto menor a quantidade de colmos e folhas em senescência colhida pelos animais, maior será o valor nutritivo da forragem consumida.

A partir segundo período de utilização a pastagem manejada com intervalos DEF apresentou maior relação folha: colmo $(\mathrm{P}=0,0122$; Tabela 1). O intervalo entre pastoreios FIXO resultou em dossel com maior altura do perfilho estendido $(\mathrm{P}=$ 0,0296; Figura 1) e maior altura de pseudocolmo $(\mathrm{P}=0,0006)$. Cândido et al. (2005) relataram uma correlação negativa entre a altura de pseudocolmo (APC) e a relação folha: colmo. Gastal e Lemaire (2015) reforçam que o pseudocolmo influencia negativamente o consumo da forragem dos animais em pastejo, devido à barreira física causado pela estrutura no dossel.

A profundidade de lâminas foliares representa a diferença entre a altura média do dossel e altura dos pseudocolmo, parece ser uma característica estrutural com significativa influência sobre a ingestão de forragem no dossel e desempenho 
animal, uma vez que esta influencia a oportunidade de seleção pelos animais de partes forragem com maior valor nutritivo e menor resistência à apreensão. A profundidade de lâminas neste estudo sofreu interação entre tratamentos e ciclos de pastejo ( $\mathrm{P}=0,005$; tabela 1). Com intervalos entre pastoreio FIXO, o pasto apresentou menor profundidade de lâminas foliares. Esta condição se acentuou no terceiro ciclo de pastejo, quando a pastagem manejada com intervalos entre pastoreios de 28 dias, apresentou uma redução significativa na profundidade de lâminas do dossel.

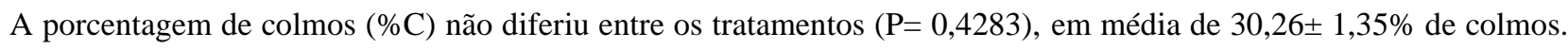
$\mathrm{O}$ intervalo entre pastoreios equivalente à duração de elongação foliar resultou em maior percentagem de folhas (\%F) e menor massa de colmos (MC) no dossel ( $\mathrm{P}<0,05$; Tabela 2); condições que podem ser favoráveis para a otimização dos processos de busca e apreensão de forragem pelos animais em pastejo. Palhano et al. (2007) afirmam que maiores participações de colmo na pastagem podem restringir o consumo de forragem, em função da redução no valor nutritivo da forragem e da restrição física à ingestão de forragem, uma vez que o comportamento ingestivo é sensível a variações na estrutura do dossel forrageiro. Ainda, Nascimento Júnior et al. (2013) discutem que o componente com melhor valor nutritivo das plantas é a folha.

Tabela 2. Porcentagem de folhas (\%F), massa de colmos (MC) e número de folhas em elongação (NFE) de Azevém Anual cv. Estanzuela 284, sob lotação rotativa.

\begin{tabular}{lcccc}
\hline \multirow{2}{*}{ Variáveis } & \multicolumn{2}{c}{ Intervalos entre pastoreio } & & E.P.* \\
\cline { 2 - 5 } F $(\%)$ & DEF & FIXO & $\pm 0,93$ & 0,0015 \\
\cline { 2 - 5 } MC (kg/ha de MS) & $59,99 \mathrm{~A}$ & $54,73 \mathrm{~B}$ & $\pm 5,61$ & $<0,0001$ \\
NFE (folhas/ perfilho) & $968,47 \mathrm{~B}$ & $1124,85 \mathrm{~A}$ & $\pm 0,07$ & 0,0079 \\
\hline
\end{tabular}

*Erro Padrão da média, **Probabilidade entre tratamentos, letras distintas na linha indicam que as médias diferem entre si pelo teste de Tukey $(\mathrm{P}<0,05)$.

Fonte: Autores

As variáveis taxa de aparecimento foliar (TAF), taxa senescência de foliar (TSF), número de folhas verdes (NFV) e densidade populacional de perfilhos (DPP) não diferiram entre períodos e entre tratamentos ( $\mathrm{P}>0,05)$. $\mathrm{O}$ azevém apresentou em média, 2,89 $\pm 1,55$ folhas verdes e $2845,3 \pm 356,35 \mathrm{perfilhos} / \mathrm{m}^{2}$.

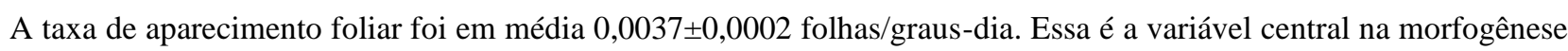
vegetal, pois influencia as características estruturais do dossel (Lemaire \& Chapman, 1996) e, dentre as variáveis morfogênicas, é a que sofre menor influência de manejo da pastagem. Para Cândido et al. (2005) são necessários longos períodos de descanso para a interferência nas características morfogênicas.

A TSF, em média 0,0252 $\pm 0,03 \mathrm{~cm} / \mathrm{graus}-$ dia, foi semelhante à relatada por Duchini et al. (2016) para azevém cv. Comum. Segundo Taiz et al. (2017), a senescência foliar é fortemente influenciada pela expressão gênica e independente do manejo de intervalos entre pastoreios.

O número de folhas em elongação foi superior para o intervalo entre pastoreio FIXO (P=0,0079; Tabela 2). Um maior número de folhas em expansão pode ser visto como uma estratégia de renovação do dossel, uma vez que as folhas jovens apresentam maiores taxas fotossintéticas por unidade de área do que as folhas maduras e outros componentes da planta. E, em condições de elevada quantidade de forragem e material senescente retidos em pastos com desfolhas pouco intensas e frequentes, as folhas em expansão podem desempenhar um importante papel na ciclagem de nitrogênio, a partir da remobilização deste nutriente das estruturas em senescência para folhas em expansão.

As variáveis taxa de elongação foliar (TEF) e número de folhas em senescência (NFS) foram influenciadas pelos períodos de ocupação da pastagem ( $\mathrm{P}<0,05$; Tabela 3 ). A redução nos valores de elongação foliar observados no terceiro ciclo 
de pastejo provavelmente se deve à menor disponibilidade hídrica, uma vez que as precipitações pluviométricas observadas entre meados de agosto e meados de setembro foram cerca de $31 \%$ inferiores à média esperada para este período. A taxa de elongação foliar é uma característica morfogênica bastante sensível às deficiências em umidade do solo, já que as plantas param o crescimento de folhas muito antes dos processos de fotossíntese e divisão celular (Duarte et al., 2019).

Tabela 3. Taxa de elongação foliar (TEF) e número de folhas em senescência (NFS) em azevém anual cv. Estanzuela 284, sob lotação rotativa.

\begin{tabular}{cccccc}
\hline & \multicolumn{5}{c}{ Períodos } \\
\cline { 2 - 4 } Variáveis & 1 (julho) & 2 (agosto) & 3 (setembro) & P** & E.P.* \\
\hline TEF & $0,152 \mathrm{~A}$ & $0,161 \mathrm{~A}$ & $0,116 \mathrm{~B}$ & 0,0012 & 0,006 \\
NFS & $0,98 \mathrm{~B}$ & $1,39 \mathrm{~A}$ & $1,50 \mathrm{~A}$ & 0,0004 & 0,006 \\
\hline
\end{tabular}

TEF (cm/graus-dia), *Erro Padrão da média, **Probabilidade entre períodos, letras distintas na linha indicam que as médias diferem entre si pelo teste de Tukey $(\mathrm{P}<0,05)$.

Fonte: Autores

O NFS aumentou ao longo dos períodos de utilização da pastagem ( $\mathrm{P}<0,05$; Tabela 3). A senescência abrange todos os processos de deterioração que acompanham o envelhecimento e que conduz a morte de um órgão ou da planta toda (Simioni et al., 2014). A elevação do número de folhas em senescência e/ou taxas de senescência é um processo natural ao longo da utilização da pastagem e decorre do avanço do ciclo fenológico das gramíneas anuais. Os resultados observados também têm relação com a elevação nas temperaturas diárias, já que a senescência é acelerada pela temperatura de forma linear (Lemaire \& Chapman, 1996) e, especialmente no terceiro ciclo, também podem ter sido afetados pela baixa precipitação pluviométrica ocorrida.

\section{Conclusão}

Os intervalos entre pastoreios estudados não influenciaram as características morfogênicas avaliadas.

O intervalo entre pastoreio FIXO resultou em estrutura do dossel menos favorável, com menor relação folha: colmo, menor profundidade de lâminas e maior massa de material morto.

Sugere-se que novos trabalhos sejam conduzidos com foco na qualificação dos processos de manejo de pastagens.

\section{Agradecimentos}

Ao Instituto Federal Farroupilha Campus Alegrete pelo apoio para realização da pesquisa.

\section{Referências}

Cândido, M. J. D., Gomide, C. A. M., Alexandrino, E., et al. (2005). Morfofisiologia do Dossel de Panicum maximum cv. Mombaça sob Lotação Intermitente com Três Períodos de Descanso. Revista Brasileira de Zootecnia, 34 (2): 406-415. https://doi.org/10.1590/S1516-35982005000200007

Carrère, P., Louault, F., \& Soussana, J. F. (1997). Tissue turnover within grass-clover mixed swards grazed by sheep. Methodology for calculating growth, senescence and intake fluxes. Journal of Applied Ecology, 34: 333-348. https://doi.org/10.2307/2404880

Carvalho, P. C. F., Ribeiro Filho, H., \& Poli, C. (2001). Importância da estrutura da pastagem na ingestão e seleção de dietas pelo animal em pastejo. In: Reunião anual da Sociedade Brasileira de Zootecnia, 38, Piracicaba. Anais...

Comissão De Química E Fertilidade Do Solo. (2004). Manual de adubação e de calagem para os Estados do Rio Grande do Sul e de Santa Catarina/ Sociedade Brasileira de Ciência do Solo (10a ed). Porto Alegre.

Confortin, A. C. C., Quadros, F. L. F., Rocha, M. G., et al. (2010). Morfogênese e estrutura de azevém anual submetido a três intensidades de pastejo. Acta Scientarum. Animal Sciences, 32 (4): 385-391. https://doi.org/10.4025/actascianimsci.v32i4.8657 
Duarte, C. F. D., Prochera, D. L., Paiva, L. M., et al. (2019). Morfogênese de braquiárias sob estresse hídrico. Arquivo Brasileiro de Medicina Veterinária e Zootecnia, 71 (05): 1669-1676. https://doi.org/10.1590/1678-4162-10844

Duchini, P. G., Guzatti, G. C., Ribeiro-Filho, H. M. N., et al. (2016). Intercropping black oat (Avena strigosa) and annual ryegrass (Lolium multiflorum) can increase pasture leaf production compared with their monocultures. Crop and Pasture Science, 67 (5): 574-581. https://doi.org/10.1071/CP15170

Empresa Brasileira De Pesquisa E Agropecuária - Embrapa. (2006). Centro Nacional de Pesquisa de Solos. Sistema Brasileiro de Classificação de Solos. Brasília: Embrapa-SPI; Rio de Janeiro: Embrapa-Solos.

Euclides, V. P. B., Montagner, D. B., Barbosa, R. A., et al. (2014). Manejo do pastejo de cultivares de Brachiaria brizantha (Hochst) Stapf e de Panicum maximum Jacq. Revista Ceres, 61 (Suppl): 808-818. https://doi.org/10.1590/0034-737x201461000006

Fernandes, L. O., Reis, R. A., Paes, J. M. V., et al. (2015). Desempenho de bovinos da raça Gir em pastagem de Brachiaria brizantha submetidos a diferentes manejos. Revista Brasileira Saúde Produção Animal, 16 (1): 36-46. https://doi.org/10.1590/S1519-99402015000100004

Fontaneli, R. S., Santos, H. P., Fontaneli, R. S., et al. (2012). Gramíneas forrageiras anuais de inverno. In: Forrageiras para Integração Lavoura-PecuáriaFloresta na Região Sul-Brasileira. Brasília: Embrapa.

Gastal, F., \& Lemaire, G. (2015). Defoliation, shoot plasticity, sward structure and herbage utilization in pasture: review of the underlying ecophysiological processes. Agriculture, 5 (4): 1146-1171. https://doi.org/10.3390/agriculture5041146

Heringer, I., \& Carvalho, P.C.F. (2002). Ajuste da carga animal em experimentos de pastejo: uma nova proposta. Ciência Rural, 32 (4): 675-679. https://doi.org/10.1590/S0103-84782002000400021

INMET, Instituto Nacional De $\quad$ Metereologia. (2016). Estações $\quad$ Automáticas $\quad$ Gráficos. http://www.inmet.gov.br/portal/index.php?r=home/page\&page=rede_estacoes_auto_graf.

Jochims, F., \& Ludtke, A. (2020). Severidade de desfolhação e sua influência no intervalo entre cortes, na produtividade e no valor nutritivo do capim-elefante BRS Kurumi. Agropecuária Catarinense, 33 (2), 42-47. https://doi.org/10.52945/rac.v33i2.756

Lemaire, G., \& Chapman, D. (1996) Tissue flows in grazed plant communities. In: The ecology and management of grazing systems. Wallingford: CAB International.

Nascimento Júnior, D., Vilela, H. H., Sousa, B. M. L., et al. (2014). Fatores que afetam a qualidade de plantas forrageiras. In: Forragicultura: Ciência, Tecnologia e Gestão dos Recursos Forrageiros. Jaboticabal: Funep.

Palhano, A. L., Carvalho, P. C. F., Dittrich, J. R., et al. (2007). Características do processo de ingestão de forragem por novilhas holandesas em pastagem de Capim-Mombaça. Revista Brasileira de Zootecnia, 36 (4): 1014-1021. https://doi.org/10.1590/S1516-35982007000500005

Pereira, A. S., Shitsuka, D. M., Parreira, F. J., et al. (2018). Metodologia da pesquisa científica. Santa Maria: UFSM/NTE.

Prache, S., \& Peyraud, J. (2001). Foraging: Behavior and intake in temperate cultivated grassland. In: International Grassland Congress. 19. Proceedings...

Quadros, F. L. F., Garagorry, F. C., Carvalho, T. H. N., et al. (2011). Utilizando a racionalidade de atributos morfogênicos para o pastoreio rotativo: experiência de manejo agroecológico em pastagens naturais do Bioma Pampa. Cadernos de Agroecologia/Revista Brasileira de Agroecologia, 6: 716-720.

Reis, R. A., Barbero, R. P., \& Hoffmann, A. (2016). Impactos da qualidade da forragem em sistemas de produção de bovinos de corte. Informe Agropecuário, 37 (292): 36-53.

SILVA, S. C. da. (2015). O manejo do pastejo e a intensificação da produção animal em pasto. Caderno de Ciências Agrárias, 7 (Suppl), 80-100.

Simioni, T. A., Hoffmann, A., Gomes, F. Jr., et al. (2014). Senescência, remoção, translocação de nutrientes e valor nutritivo em gramíneas tropicais. PUBVET, 8 (13): 1551-1697.

Taiz, L., Zeiger, E., Moller, I. M., et al. (2017). Senescência vegetal e morte celular. In: Fisiologia e Desenvolvimento Vegetal. (6a ed.): Artmed.

Tonetto, C. J., Müller, L., Medeiros, S. L. P., et al. (2011). Produção e composição bromatológica de genótipos diploides e tetraploides de azevém. Zootecnia Tropical, 29 (2), 169-178. 